\title{
BARIATRIC SURGERY: A SAFE OPTION FOR TREATMENT OF OBESITY IN PATIENTS WITH SCHIZOPHRENIA
}

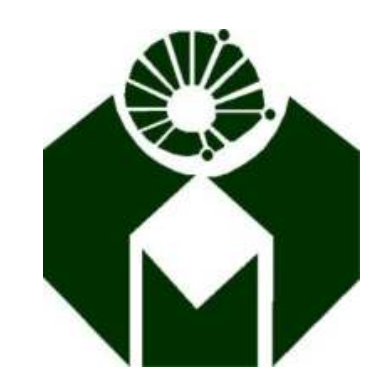

Inaiah Muritiba Sampaio (inaiahmuritiba@gmail.com); Maíra Esteves Brito (maira.ebrito@yahoo.com.br); Areta Cavalcanti Ferreira (aretacavalcanti@yahoo.com.br); Paulo Dalgalarrondo (pdalga@fcm.unicamp.br); Amilton dos Santos Junior (Amilton@fcm.unicamp.br); Lício Augusto Velloso (lavelloso@fcm.unicamp.br); Elinton Adami Chaim (chaim@fcm.unicamp.br)

\section{Faculdade de Ciências Médicas - Universidade Estadual de Campinas - UNICAMP}

\section{INTRODUCTION}

Although bariatric surgery has become a recognized treatment for obesity, its utility among patients with schizophrenia has not been extensively studied. A few studies have reported similar weight loss outcomes among these patients, but the exacerbation of the mental illness has been only minimally studied.

\section{MATHERIALS AND METHODS}

Five patients with schizophrenia and severe obesity were studied. The surgeries were performed between August and September 2017. Patients were followed for one year after the procedure, and changes in body mass index (BMI) and excess weight loss were compared, considering the period prior to the surgeries, and both six and twelve months after them. For the evaluation of psychotic symptoms, the Positive and Negative Syndrome Scale (PANSS) was used.

\section{RESULTS}

The sample was composed by four female participants and one male $(80 \%$ female), aged between 29 and 48 years $(M=39,4)$ and BMI between 39 and $52(M=42,6)$, as show in table 1 .

A significant trend of $\mathrm{BMI}$ reduction was seen 12 months after the surgeries, as well as a great decrease of percentage of excess weight (tables 2 and 3 ).

Table 1. Clinical data

\begin{tabular}{cccc} 
Patient & Sex & Age & $\begin{array}{c}\text { IMC } \\
(\mathbf{k g} / \mathbf{m} 2)\end{array}$ \\
\hline 1. & F & 48 & 52 \\
\hline 2. & M & 38 & 39 \\
\hline 3. & F & 39 & 41 \\
4. & F & 29 & 42 \\
5. & F & 43 & 39 \\
\hline
\end{tabular}

Table 2. BMI changes between before(T0) and 12 months after (T12) bariatric surgery.

\begin{tabular}{|c|c|c|c|}
\hline & TO* & T12* & $\mathbf{p}^{\star \star}$ \\
\hline BMI & $43,4 \pm 5,2$ & $27,9 \pm 1,8$ & 0,043 \\
\hline
\end{tabular}

*Data are expressed as means and standard deviation.

*Statistical significance $p=0,05$, calculeted using the Wilcoxon test.

Table 3. Excesse weight loss changes between 6(T6) and 12 months(T12) after bariatric surgery.

\begin{tabular}{|c|c|c|c|}
\hline & $\mathrm{T}^{*}$ & $\mathrm{~T}_{12}^{*}$ & $p^{\star \star}$ \\
\hline $\begin{array}{c}\% \text { excess } \\
\text { weight loss }\end{array}$ & $73,5 \pm 8,1$ & $83,9 \pm 11,2$ & 0,043 \\
\hline
\end{tabular}

*Data are expressed as means and standard deviation.

*Statistical significance $p=0,05$, calculeted using the Wilcoxon test.

None of the patients had recrudescence of the psychotic symptoms. None of them presented positive, negative or mixed symptoms of schizophrenia. No significant difference was seen between the PANSS's results before and one year after bariatric surgery (table 3 ).

Table 4. Psychopatological evaluation though the PANSS scale before(T0) and 12 months after(T12) the bariatric surgery.

\begin{tabular}{cccc} 
PANSS & T0* $^{*}$ & T12 $^{*}$ & $\mathbf{p}^{\star *}$ \\
\hline Positiva & $7,8 \pm 1,8$ & $7,0 \pm 0,0$ & 0,317 \\
Negativa & $8,6 \pm 2,5$ & $7,8 \pm 1,3$ & 0,180 \\
Geral & $19,8 \pm 6,4$ & $18,4 \pm 2,3$ & 0,854 \\
\hline
\end{tabular}

${ }^{*}$ Data are expressed as means and standard deviation.

*Statistical significance $p=0,05$, calculeted using the Wilcoxon test.

\section{CONCLUSIONS}

The results showed that bariatric surgery may be as effective for weight loss in patients with schizophrenia as for patients without mental illness. It is also a safe method, when there's a careful selection of patients. These findings demonstrate that bariatric surgery is a viable obesity treatment option for patients with schizophrenia.

Patterson EJ, Urbach DR, Swanström LL. A comparison of diet and exercise therapy versus laparoscopic Roux-en-Y gastric bypass surgery for morbid obesity: a decision analysis model. J Am Coll Surg [Internet]. março de 2003 [citado 10 de fevereiro de 2016];196(3):379-84.

Shelby SR, Labott S, Stout RA. Bariatric surgery: a viable treatment option for patients with severe mental illness. Surg Obes Relat Dis [Internet]. Elsevier; 2015;1-7

Fuchs HF, Laughter V, Harnsberger CR, Broderick RC, Berducci M, DuCoin C, et al. Patients with psychiatric comorbidity can safely undergo bariatric surgery with equivalent success. Surg Endosc [Internet]. 2015; Recuperado de: http://www.ncbi.nlm.nih.gov/pubmed/25847138. 